\title{
Polychlorinated dibenzo-p-dioxin/dibenzo furans (PCDD/Fs) contamination in sediments and fish from Msimbazi river in Dar es Salam-Tanzania: patterns, sources and their exposure to humans
}

Christina Pius ( $\square$ tina84f@yahoo.com )

Mkwawa University College of Education

Pulane Koosaletse-Mswela

University of Botswana

Kwenga Sichilongo

University of Botswana

Oagile Dikinya

University of Botswana

\section{Research Article}

Keywords: PCDD/Fs, WHO2005-TEQg-1, Msimbazi river, sediments, cat fish, GCXGC-TOFMS

Posted Date: January 21st, 2022

DOI: https://doi.org/10.21203/rs.3.rs-1200135/v1

License: (c) (i) This work is licensed under a Creative Commons Attribution 4.0 International License.

Read Full License 


\section{Abstract}

Results of a GCXGC-TOFMS determination of PCDD/Fs in sediments and cat fish samples collected from Msimbazi river, are presented here. PCDD/Fs congeners in sediments ranged from 2.0 to 393.0 and 0.7 to $654.8 \mathrm{pg} / \mathrm{g}$ in the dry and wet season respectively. 1,2,3,4,7,8,9-HepCDF was detected at the highest concentration but all were lower than the United States of America (USA) action level of $1000 \mathrm{pg} / \mathrm{g}$. Toxicity for each of the sampling points ranged from 19.7 to 36.5 with a mean concentration of $27.0 \mathrm{pg}$ WHO $2005^{-T E Q ~ g}{ }^{-1}$ in the dry season and 2.0 to 38.7 with a mean concentration of $20.7 \mathrm{pg} \mathrm{WHO} 2005^{-T E Q}$ $\mathrm{g}^{-1}$ in the wet season. Analysis of variance (ANOVA) showed that there was no significance difference between PCDD/Fs TEQ during the dry and the wet season, $(P=0.08), a=0.05)$. The highest TEQ value was estimated at Jangwani in the wet season. Toxicity of PCDD/Fs in cat fish collected from Msimbazi river ranged from 9.3 to 145.2 , with a mean of $61.2 \mathrm{pg} \mathrm{WHO}_{2005} \mathrm{TEQg}^{-1}$. Tetrachlorodibenzo dioxin $(2,3,7,8-$ TCDD), was detected in all fish samples and ranged from 3.5 to 12.7 with a mean of $8.1 \mathrm{pg} / \mathrm{g}$.

\subsection{Introduction}

Polychlorinated dibenzo-p-dioxin (PCDDs) and polychlorinated dibenzo furans (PCDF) are among persistent organic pollutants (POPs) which are ubiquitous in the environment, primarily as unintentional by products of combustion. They persist, bioaccumulate through the food chain and cause adverse effects on human being and the ecosystem. Initiatives have been taken globally to reduce the production and release of intentionally produced POPs such as pesticides and industrial chemicals to the environment. Although PCDD/Fs can be formed naturally in forest fires and volcanic eruptions, their main sources are anthropogenic, such as the open burning and incineration of wastes, as well as emissions from industrial processes (Jones. and De Voogt 1999; Pan et al. 2010; Rovira et al. 2010; UNEP 2001). Monitoring of POPs is of great concern because of the adverse effects that they inflict on human beings and the environment. PCDD/Fs have acute and chronic effects on the immune, nervous, endocrine and reproductive systems, including their carcinogenic potential (Bi et al. 2020; Mikolajczyk et al.2021; USEPA 1985).

PCDD/Fs enter aquatic ecosystems and persist for long periods of time and bioaccumulate and biomagnify through the food chain. Studies have reported their presence in sediments and in aquatic species such as fish (Lee et al. 2007; Mikolajczyket al. 2021; Shin et al. 2020). Exposure of aquatic organisms to PCDD/Fs can also affect them in different ways such as mortality, decreased growth rate, and weight loss. There are several factors which affect the accumulation of PCDD/Fs in the marine organism. Common factors are body weight, lipid content and trophic levels. Fish is relatively higher in the food chain, hence they can bioaccumulate PCDD/Fs in their fat tissues in muscles, 100,000 times the surrounding environment (Castro et al. 2013). Catfish lives at the bottom of the river and feeds on sediments hence they accumulate PCDD/Fs adsorbed on the sediments. This underscores the need to assess PCDD/Fs contaminations in sediments and fish in rivers. 
Msimbazi River flows across Dar es Salaam City from the higher areas of Kisarawe in the Coastal region of Tanzania. It passes along the industrial and residential areas and discharges into the Indian Ocean. The river is about $35 \mathrm{~km}$ long, with three tributaries Sinza, Ubungo and Luhanga rivers (Kondoro 1992). The river is important to dwellers who depend on vegetable cultivation beside the river. Msimbazi river catchment area is surrounded by industrial effluents, sewer effluents, abattoir effluents, hospital waste incinerator, power station, high traffic roads and massive informal settlements. All these are speculated to be potential sources of PCDD/Fs (Kassenga 2009; Mbuligwe and Kaseva 2005; Wirgin and Chambers 2021). Furthermore the river is misused by people around, in which during dry season massive wastes are dumped and burned. As a result of these activities, there is need to establish the levels of PCDD/Fs in the Msimbazi river and also to predict their sources and exposure of humans through cat fish consumption in order to safegurd human health and the ecosytem.

There has been a historical trend of pollution in Msimbazi river dating back to 1986. Several studies have been conducted in this river in order to assess on heavy metals and organic matter pollution (Ak'habuhaya and Lodenius 1988; Chanzi 2017; Mbuligwe and Kaseva 2005; Mihale 2021; Miraji et al. 2020; Sawe et al. 2021). Literature showed that todate, no results have been reported on the concentrations of PCDD/Fs despite there being a myriad of potential sources of these pollutants. The aim of this study thus, was to establish levels, distribution patterns and sources of PCDD/Fs in Msimbazi river and establish toxin exposure pattern of humans through fish consumption.

\subsection{Materials And Methods}

\subsection{Chemicals and reagents}

For extraction, HPLC grade toluene, hexane and dichloromethane were purchased from Riedel-de Haën (Germany), sulphuric acid (ACS reagent), copper powder, basic alumina and high purity silica gel (100-200 mesh) were obtained from Sigma Aldrich, Poole, Dorset, Dulin, (Republic of Ireland). Anhydrous sodium sulphate was purchased from Rochelle chemicals, Merck, Central Carolina (USA). Cellulose extraction thimbles were purchased from Whatman International Ltd (England). Internal standards (EDF 4145) isotopically labeled and unlabeled PCDD/Fs standards (EDF 4999), were purchased from Cambridge Isotope Laboratories, CIL, Andover, MA, (USA).

\subsection{Sediment sampling}

Purposive sampling of sediments was conducted at Msimbazi River during the dry and the wet seasons. Sampling points were chosen based on identified industrial or biomass burning activities that were speculated to be point sources of PCDD/Fs as seen in Figure 1. Samples were collected from the main Msimbazi river and its main tributaries such as Luhanga, Ubungo, and Sinza (Figure 1). One sample i.e. MO was collected upstream and used as a control to assess the contamination of PCDD/Fs exclusive of the speculated point sources. 
The Sediments were coded M0-M7, and were samples at depths of $10-20 \mathrm{~cm}$ using a hand corer which was $30 \mathrm{~cm}$ long and $6 \mathrm{~cm}$ internal diameter (id). Three (3) subsamples were obtained from each sampling point to form a composite sample and mixed on site. After mixing and homogenizing, about $300 \mathrm{~g}$ of sample were wrapped in an aluminum foil and zipped into labeled sample bags. Coordinates as seen in Table 1, for each sampling point were recorded using a Geographic Positioning System (GPS).

Table 1 Sampling sites and their coordinates along Msimbazi river and its tributaries

\begin{tabular}{|ll|}
\hline Sampling stations & Coordinates \\
\hline M0 & $-6.857477,39.187834$ \\
\hline M1 & $-6.839833,39.222838$ \\
\hline M2 & $-6.82304,39.23929$ \\
\hline M3 & $-6.815909,39.26247$ \\
\hline M4 & -6.8184739 .23473 \\
\hline M5 & $-6.810875,39.265141$ \\
\hline M6 & $-6.80080,39.26209$ \\
\hline M7 & $-6.795605,39.28066$ \\
\hline
\end{tabular}

Sampling in the dry season was done from January to February 2017 and in the wet season from May to June 2017. All the samples were transferred to the University of Dar es Salaam, Department of Chemistry and stored at $4^{\circ} \mathrm{C}$ until they were shipped by air on cold chains (USEPA 1994) to the University of Botswana for extraction and analysis.

\subsection{Fish sampling}

Random fish sampling from Msimbazi river was done by collecting fish of different sizes. Samples were wrapped in an aluminum foil, placed in sample bags then in an ice cooled box. It was stored frozen until it was shipped by air on cold chains to the University of Botswana for extraction and analysis (USEPA 1994).

\subsection{Sediment extraction and clean up before PCDD/F analysis}

Sediment samples were air dried on aluminium foil, ground and sieved using a $2 \mathrm{~mm}$ mesh sieve before extraction. USEPA method 1613 was used for sediments extraction in which forty grams $(40 \mathrm{~g})$ of samples was spiked with ${ }^{13} \mathrm{C}$ labeled standard containing all the 17 congeners of PCDD/Fs then mixed with an equal amount of anhydrous sodium sulfate $\left(\mathrm{Na}_{2} \mathrm{SO}_{4}\right)$ then soxhlet extracted for 16 hours with toluene. The extracts were concentrated to $1 \mathrm{~mL}$ using a rotary evaporator. The first clean-up was performed by eluting the extracts through a multilayer silica gel column. The extracts were then 
concentrated to $1 \mathrm{~mL}$ and further clean-up was performed through an alumina column from which PCDD/Fs were eluted using 50\% dichloromethane in hexane (USEPA 1994).

\subsection{Fish extraction before PCDD/Fs analysis}

The US EPA Method 1613 with few modifications was used for extraction. Composite samples were made from fish samples collected from the same sampling point with approximately the same length. All fish were deboned and muscles were blended using a food processor to form homogenous samples. Then, 30 $\mathrm{g}$ of homogenized fish samples were placed in $500 \mathrm{~mL}$ bottles with screwed lids, spiked with ${ }^{13} \mathrm{C}$ labeled standard containing all the 17 congeners of PCDD/Fs. Two hundred (200) $\mathrm{mL}$ of $6 \mathrm{M} \mathrm{HCl}$ were added to the sample followed by $200 \mathrm{~mL}$ of a mixture of methylene chloride and hexane (1:1). The same amount was added to the quality control aliquots. The mixture was shaken for 10 minutes and vented in the hood to release pressure then placed on a shaker, which ensured the mixture was in constant motion for 12 hours. The mixture was then removed from the shaker and allowed to settle so that the aqueous layer could be separated. The solvent was then decanted with a glass fibre and filter containing $10 \mathrm{~g}$ of granular anhydrous $\mathrm{Na}_{2} \mathrm{SO}_{4}$. After extraction, several acidic silica was used to remove oil then cleaned-up and was ready for analysis (USEPA 1994, 2008).

\subsection{GCXGC-TOFMS instrumentation}

GCxGC-TOFMS instrument housed at the University of Witwatersrand in South Africa was used for analysis. The system is a Pegasus 4D, Leco Corp., St. Joseph, (USA), equipped with a multi-purpose autosampler (Gerstel, Mülheim, Germany). Liquid nitrogen was used for cold jets and air from an in-house system during modulation. Instrument control and data processing were carried out using ChromaTOF software, version 4.5, Leco Corp., St. Joseph, MI (USA). In this study, one pair of columns i.e. the Rxi -5 Sil MS / Rtx-200 for GCxGC from the Restek Corporation, Bellefonte, PA (USA) were optimized for primary and secondary separations.

\subsection{Quality control, Standards and method optimization using isotope dilution}

The EDF 7999 standard containing all 17 congeners of PCDD/Fs at different concentrations was used for method optimization. The concentration of the original standard stock solution was $400 \mathrm{pg} / \mu \mathrm{l}$ for tetrachlorodibenzo dioxin /furans, 4000 pg/ $\mu$ l for octachlorodibenzo dioxins /furans and 2000 pg/ $\mu$ l for the rest of the congeners. Dilution was done 100 to 200 fold to prepare calibration standards. Isotope dilution was used for the calibration of the native compounds (PCDD/Fs) with labelled analogs according to the USEPA method 1613. Since the native and the labelled compounds respond in a similar way at a certain concentration, the relative response (RR) of each native i.e. relative to its labelled analog was determined by using the area response of the exact $m / z$ ratios for each calibration standard. The same amounts of labelled compounds were added to every sample prior to analysis. RR values were used with the initial calibration data to determine the concentrations of PCDD/Fs in the extracts. The quality control parameters i.e. the linearity, the percent recoveries, accuracy and precision have been reported from this research group (Pius et al. 2020). 


\subsection{Results And Discussion}

\subsection{Dry and wet season organic matter content (OMC) in sediments from Msimbazi River}

Dry and wet season \% OMC varied from 0.05 to 4.55 , mean 0.93 and from 0.01 to 9.39 , mean 1.63 respectively. The slightly higher \% OMC during the wet season could have been due to heavy rains which lead to erosion and deposition of organic matter from human habitats to the river (Fig. 2A and B). A similar study by (Carreira et al. 2015) reported the influence of the Paraíba do Sul River in Brazil, as a source and distributor of organic matter in sediments. They found high organic matter content in river sediments during the wet season. Although the OMC in this study was slightly higher during the wet season, ANOVA showed that there was no significant difference for the average OMC content in the dry and wet season $(p=0.58, a=0.05)$. Since the analysis was performed at two different depths i.e. the upper and lower, it became imperative to correlate the two sampling levels. In the dry season, the \% $\mathrm{OMC}$ ranged from 0.05 to 2.15 with a mean of 0.84 for the upper level sediments while it ranged from 0.05 to 4.55 with a mean of 1.033 for lower level sediments. In the wet season, the \% OMC ranged from 0.03 to 8.16 , with a mean 1.50 for upper level sediments and ranged from 0.01 to 9.39 , a mean of 1.75 for lower level sediments. Although there was a slight difference between the (A) \% OMC in the upper and lower level sediments, ANOVA showed that there was no significant difference in both the dry and the wet seasons $(p=0.77$ and $0.88, a=0.05$ ). This comfirmed that both the upper and lower organic matter originated from the same source and justified performing PCDD/Fs analysis for a homogenous mixture of the upper and lower sediments.

Downstream closer to the Indian Ocean in samples M6, M7, wM6 and wM7, the \% OMCs were higher compared to up-stream samples in both the dry and the wet season. This could be due to the deposition and accumulation of organic matter from all tributaries. The same results were reported in the Paraíba do Sul River in Brazil study (Carreira et al. 2015). Presence of organic matter in sediments of the Msimbazi river, was indicative of the presence of other organic pollutants, which justified the analysis of PCDD/Fs in the same samples.

\subsection{Dry and wet season PCDD/Fs concentration in sediments}

The concentrations of 17 congeners of PCDD/Fs in sediments during the dry and the wet seasons ranged from 2.0 to 393.0 and 0.7 to $654.8 \mathrm{pg} / \mathrm{g}$ dry weight respectively as seen in Fig. 4 and 5. Since this was the first PCDD/Fs concentration study in Tanzanian rivers, comparison was made with results from studies elsewhere. The results were compared with the United States of America (USA) action level set at 1000 $\mathrm{pg} / \mathrm{g}$ for PCDD/Fs and all were lower.

From Figures 3 and 4, congener concentrations varied between the sampling sites which indicated that the PCDD/Fs in the samples, originated from different sources. In the sample M0 collected upstream before discharged from suspected point sources, several congeners of PCDD/Fs were detected with 
PCDFs being predominant over PCDDs. This meant that the ratio of PCDDF to PCDD was greater than one and implied that their sources were mainly from open burning. This observation has been observed and reported by Everaerte and Baeyens (2002).

In both the dry and the wet season, regardless of the sampling point, the dominant congeners were 1,2,3,4,6,7,8-HepCDD, 1,2,3,4,6,7,8-HepCDF, 1,2,4,7,8-PeCDD, OctaCDD and TCDF. High concentrations of highly chlorinated-substituted PCDD/Fs such as Octa and Hepta signify atmospheric deposition as the major source of PCDD/F. Several studies have also reported the release of PCDD/Fs especially highly chlorinated substituted congeners from engines propelled by diesel (Chang et al. 2014; Laroo et al. 2011). It is also possible that, the detected PCDD/Fs were deposited in the Msimbazi river from diesel engine vehicles from garages, car wash stations and also high traffic roads such as Morogoro, Kawawa, SamNujoma and Mandela roads near or along the river or its tributaries at different points.

During the wet season, in addition to wM0, two more sites (wM6 and wM7) had their PCDDFs concentrations higher than PCDDs. This suggests atmospheric deposition as a mojor source of PCDD/Fs. The concentration of PCDD/Fs at the sampling site close to the Indian Ocean (wM7) in the wet season was higher than during dry season (M7). Since this was the lowest point of the river, this could have been due to sediments-bound PCDD/Fs which had eroded from the upper to the lower steam of the river. Movement of sediment bound -pollutants from upper to lower steams have been reported in the literature (Dinç et al. 2021; Verta et al. 2009; Weber et al. 2008). Concentration of PCDD/Fs in samples collected at Jangwani (M5) were relatively higher than those from other sampling points. This could be in addition to accumulation of sediments-bound PCDD/Fs from other streams such as Ubungo and Luhanga, heavy traffic along Morogoro road, car wash stations, parking slots and garages.

\subsection{Toxicity potential of PCDD/Fs at different sampling points along Msimbazi river}

TEQs indicate the magnitude of toxicity of PCDD/Fs congeners relative to 2,3,7,8-TCDD which is the most toxic congener assigned a Toxic Equivalent Factor (TEF) of 1. TEQs were calculated by summation of the products of the concentration of individual congeners at every sampling point to toxic equivalent factor (TEF) established by the World Health Organization (WHO)(WHO 2005). The total PCDD/Fs concentrations varied widely from one point to another along the river and its tributaries. In the dry season, the TEQ varied from 19.7 to 36.5 , mean $27 \mathrm{pg} \mathrm{TEQ} \mathrm{WHO}_{2005} / \mathrm{g}$ and in the wet season it varied from 2.0 to 38.72 mean 20.70 pgTEQ $\mathrm{WHO}_{2005} \mathrm{~g}^{-1}$ as seen in Figure $5 \mathrm{~A}$ and $\mathrm{B}$.

During the dry season, the lowest TEQ value was found up-stream of the river (M0). This was the point before the Msimbazi River passed through the suspected point sources of contamination. Furthermore, $86 \%$ of the TEQ in this site was contributed by $1,2,3,7,8-P e C D D$. It was speculated that the PeCDD could have precipitated due to fair deposition since this was the point that was assumed not to be affected by point sources of PCDD/Fs. This observation corroborated with other studies which reported the existence of PeCDD in sediments as a result of air depositions (Sundqvist et al. 2009; Verta et al. 2007). The highest TEQ was found in Luhanga river, (M2), followed by M1 which is the main Msimbazi river at Vingunguti. All 
these points had their TEQs mainly contributed to, by low chlorinated PCDD/Fs such as PeCDD and TCDF. The elevated TEQ values in Luhanga river could be attributed to Nida textile factory which is located near the river. This also corroborates well with other studies that have reported the release of PCDD/Fs to the environment from textile industries (Huang et al. 2021; Klasmeier and McLachlan, 1998; Križanec and Majcen Le Marechal, 2006).

During the wet season, the lowest TEQ was estimated at Sinza river sampling site wM6 followed by sampling site wM7i.e. the last point before the river poured into the Indian Ocean. At this point, there was mixing of water from the ocean and the river especially during the wet season. The low TEQ of PCDD/Fs was attributed to wash out of sediment bound PCDD/Fs to the Ocean. The highest TEQ was estimated at Jangwani, sampling site wM5, a point where Ubungo and Luhanga merge with the main Msimbazi river downstream. The elevated TEQ at this point could be due to movement of sediment bound PCDD/Fs from up-stream and from other tributaries. At this point, there was high traffic and parking slots for the rapid bus transport.

\subsection{Seasonal variation of TEQ of PCDD/Fs in sediments from Msimbazi river}

Concentrations of PCDD/Fs were lower during the dry season compared to where they were detected during the wet season as seen in Figure 6.

During the dry season the water in the river had receded, and it was speculated that the sediments-bound PCDD/Fs were deposited at the riverbed. During the wet season, there was a big variation of PCDD/Fs from one sampling point to another. This could be attributed to the movement of sediment bound PCDD/Fs due to the rain water flow responsible for washing out sediments bound PCDDFs from one point to another.

However, ANOVA showed that there was no significant difference between PCDD/Fs TEQ values during the dry and the wet season, $(P=0.08), a=0.05)$. Notable was the detection of PCDD/Fs upstream of the Msimbazi River (M0), before the suspected PCDD/Fs point sources. This suggested that PCDD/Fs in Msimbazi river were not only from point sources such as industrial effluent but also atmospheric deposition as a result of open burning of wastes and biomass that are common practices in many places in Dar es Salaam.

Additionally, data was subjected to partial least squares-discriminant analysis (PLS-DA) using PLS_Toolbox - version 9.0 for MATLAB Release 23592, 2021Copyright (C) 1995 - 2021 Eigenvector Research, Inc. (PLS Toolbox 9.0, 2021). MATLAB R2021b for academic use was used in this instance. This was done in order to see if the two classes i.e. dry and wet seasons could be distinguished. The PLSDA model was built using training data and exhibited a receiver operating characteristic (ROC) curve of sensitivity in the wet season concentrations of PCDD/Fs above a threshold of 0.8 with the area under the curve (AUC) of 0.9688 while in the dry season, the values were above 0.8 and 0.9531 respectively. These model parameters were used to predict test data from which the confusion matrix showed an overall 
classification error of $12.5 \%$ which was the same at $12.5 \%$ for the prediction results. The variance was significant only up to approximately 3 latent variables as deduced from the $X$ variance captured (\%) versus the latent variable. The scores plot of latent variable (LV) 1 with variance $22.9 \%$ versus latent variable (LV) 3 with variance $11.96 \%$ is shown in Figure 7.

As seen in Figure 7, two classes were clearly distinguished for the sediment PCDD/Fs concentrations in the dry and wet seasons. Further, a biplot i.e. scores plot with latent variable 1 (LV1) carrying the same variance at $22.9 \%$ and LV3 carrying $11.96 \%$ superimposed on the loadings plot is shown in Figure 8 . From Figure 8, the wet season showed higher concentrations of PCDD/Fs which were closely correlated. The observation underscores the fact that there was movement of sediment from the sampling points where $\mathrm{PCDD} / \mathrm{Fs}$ were detected in high concentrations during the dry season, to the sampling points where they were detected in higher concentrations during the wet season.

The Variable Importance in Projection (VIP) scores versus latent variables showed the following as the most important variables: (i) 1,2,3,7,8-PeCDF (ii) 1,2,3,4,7,8-HexCDF (iii) $2,3,4,7,8-P e C D F$ (iv) $1,2,4,7,8$ PeCDD and (v) 1,2,3,6,7,8-HexCDD, 1,2,3,4,6,7,8-HepCDD, OctaCDD and 1,2,3,7,8,9-HexCDF. These PCDD/Fs contributed to the classification observed in the scores, loadings plots and qualified the observation made in Figures 3 and 4 where the dominant analytes were a subset of these latent variables.

In this study, all the sediments collected along Msimbazi river exceeded the Interim Sediment Quality Guideline (ISQG) in Canada and USA for dioxins quoted 2,3,7,7-TCDD toxicity equivalents which are 0.85 and $2.5 \mathrm{ng} / \mathrm{kg}(\mathrm{dw})$ respectively. There is a possibility that the sediments could cause detrimental effects to sensitive organisms at all trophic levels (Canadian Council of Ministers of the Environment, 2002; Cook 1993). Fifty percent (50\%) of dry and wet season sediments presented in this study exceeded the American guideline specified as a high risk to sensitive species $25 \mathrm{ng}$ TEQ/kg dw for mammalian and wildlife. Except for M0, wM1, Wm4, Wm6,and wM7 all other stations for both wet and dry seasons had their TEQs exceed the upper limit of 20 pg WHO- dw set by the European commission for Sediments.

PCDD/Fs reported in this study were lower than the levels reported in River Nile in Egypt. PCDD/Fs in the river Nile were suggested to be high due to commercial formulation of DDT in which PCDD/Fs are found as impurities (El-Kady et al. 2007). This could be the reason why their TEQs were very high. PCDD/Fs reported in this study were relatively higher than the TEQs reported in South Africa, but their sources were closely related (open burning of wood and domestic wastes small contribution from industrial activities (Nieuwoudt et al. 2009). The River Elbe, in Central Europe was reported to have higher PCDD/Fs concentrations compared to the levels in Msimbazi river reported in this study (Götz et al., 2017).

\subsection{PCDD/Fs in catfish collected from Msimbazi river}

Concentrations of PCDD/Fs congeners detected in fish samples are presented as $\log _{10}$ concetrations for clarity in Figure 9. Out of 17 congeners, four namely 1,2,4,7,8-PeCDD, 1,2,3,4,6,7,8,-HepCDD and $1,2,3,4,7,8,9-$ HepCDF were most dominant. Concentrations of these congeners were also high in 
sediments analyzed from Msimbazi river, indicating a common source of PCDD/Fs in sediments and in fish.

$\mathrm{PCDD} /$ Fs in fish collected from Msimbazi river presented in $\mathrm{WHO}_{2005}$ fresh weight ranged from 9.3 to 145.2, mean $61.2 \mathrm{pg} \mathrm{WHO}_{2005^{-}} \mathrm{TEQg}^{-1}$ as seen in Figure 10.

The TEQs estimated in fish were very high compared to values reported in sediments. This could be due to long time accumulation of PCDD/Fs in fish fat tissue compared to accumulation in sediments. The mean concentration of PCDD/Fs was higher than the European Commission regulation value (3.5 pg WHO-TEQ $\mathrm{pg} / \mathrm{g}$ ) fw for muscle meat of fish and fishery products, (European Commission 2011) suggesting a health risk for consumers of fish from Msimbazi river. 2,3,7,8-TCDD was detected in all fish samples ranging from 3.5 to 12.7 with a mean of $8.1 \mathrm{pg} / \mathrm{g}$. The minimum risk level for hazardous substances established by the Agency for Toxic Substance and Diseases Registry prescribes a minimum residue level (MRL) of $0.0002 \mathrm{ugkg}^{-1} \mathrm{day}^{-1}$ of 2,3,7,8-TCDD to be eaten on average by a person of $70 \mathrm{~kg}$ (Chou et al.1998). With a mean value of $8.1 \mathrm{pg} / \mathrm{g}$ TCDD obtained in this study, even less than $1 \mathrm{~g}$ of fish per person per day would still exceed the MRL. This surfaces a probable high risk of consuming catfish from Msimbazi river. About $50 \%$ of fish samples had their PCDFs concentrations higher than PCDDs, so the ratio of PCDF to PCDD was higher than 1 . This suggested that the PCDD/Fs, which accumulated in fish, could have been from open burning of waste and biomass.

Results obtained from this study were higher than values obtained in lake whitefish from Canadian Great lakes (22-54 TEQ g ${ }^{-1}$ ) (Bhavsar et al. 2008) and those reported in fish from Lake Victoria in East Africa i.e. 0.001 to 0.09 WHO-TEQ pg/g (Ssebugere et al., 2013)

\subsection{Conclusion}

Results demonstrate that sediments and fish were contaminated by PCDD/Fs at levels higher than international standards such as the USA action levels for PCDD/Fs that can cause detrimental effects to human and aquatic life. ANOVA and PLS-DA statistical evaluations showed that elevated concentrations of PCDD/Fs in some segments of the river, arose due to movement of sediment bound PCDD/Fs from the upper to the lower river stream. There was wash out of sediment bound PCDD/Fs at points close to the Indian ocean suggesting a large environmental impact of PCDD/Fs from the Msimbazi river. The amount of organic matter positively correlated with PCDD/Fs concentration, suggesting common sources with PCDD/Fs. Classification of congeners suggested different sources of PCDD/Fs. PCDD/Fs were also detected up-stream of the Msimbazi river and attributed to atmospheric deposition from open burning of wastes and biomass which is a common practice in Dar es Salaam, Tanzania. The concentration of TCDD in fish exceeded the Agency for Toxic Substance and Diseases Registry MRL thus posing a probable high risk to people whose dietary requirements depend on fish from Msimbazi river

\section{Declarations}


Acknowledgements

The authors would like to thank the University of Botswana for material support. C. Pius thanks Transdisciplinary Training for Resource Efficiency and Climate Change Adaptation in Africa (TRECCAfrica) for financial support.

\section{Funding}

The authors would like to thank the University of Botswana for material support. C. Pius thanks Transdisciplinary Training for Resource Efficiency and Climate Change Adaptation in Africa (TRECCAfrica) for financial support

Competing Interest

The authors have no relevant financial or non-financial interests to disclose

\section{Author Contributions}

Sample collection, preparation and analysis were performed by Christina Pius. The first draft of the manuscript was written by Christina Pius. Authors Pulane Koosaletse-Mswela, Kwenga Sichilongo, Oagile Dikinya commented on previous versions of the manuscript. All authors read and approved the final manuscript.

\section{Ethical Approval}

Not applicable

Consent to Participate

Not applicable

Consent to Publish

Not applicable

Declaration

The author has no conflict of interest associated with the work reported in this manuscript. This manuscript has not been published and it is not under consideration for publication elsewhere.

\section{References}

1. Ak'habuhaya J, Lodenius M (1988) Metal pollution of river Msimbazi, Tanzania. Environ Int 14(6):511-514. https://doi.org/10.1016/0160-4120(88)90412-6 
2. Bhavsar SP, Awad E, Fletcher R, Hayton A, Somers KM, Kolic T, Reiner EJ (2008) Temporal trends and spatial distribution of dioxins and furans in lake trout or lake whitefish from the Canadian Great Lakes. Chemosphere 73(1):S158-S165. https://doi.org/10.1016/j.chemosphere.2007.05.100

3. Bi C, Chen Y, Zhao Z, Li Q, Zhou Q, Ye Z, Ge X (2020) Characteristics, sources and health risks of toxic species (PCDD/Fs, PAHs and heavy metals) in PM2. 5 during fall and winter in an industrial area. Chemosphere 238:124620. https://doi.org/10.1016/j.chemosphere.2019.124620

4. Canadian Council of Ministers of the Environment (2002) Canadian environmental quality guidelines, vol 2. Canadian Council of Ministers of the Environment

5. Carreira RS, Cordeiro LG, Oliveira DR, Baeta A, Wagener AL (2015) Source and distribution of organic matter in sediments in the SE Brazilian continental shelf influenced by river discharges: An approach using stable isotopes and molecular markers. J Mar Syst 141:80-89. https://doi.org/10.1016/j.jmarsys.2014.05.017

6. Castro. J, Rotllant. G, Ábalos. M, Parera. J, Dachs. J, Joan. B (2013) Accumulation of dioxins in deepsea crustaceans, fish and sediments from a submarine canyon (NW Mediterranean). Prog Oceanogr 118:260-272. https://doi.org/10.1016/j.pocean.2013.07.017

7. Chang Y-C, Lee W-J, Wang L-C, Yang H-H, Cheng M-T, Lu J-H, Young L-H (2014) Effects of waste cooking oil-based biodiesel on the toxic organic pollutant emissions from a diesel engine. Appl Energy 113:631-638. https://doi.org/10.1016/j.apenergy.2013.08.005

8. Chanzi G (2017) Heavy Metal Pollution Assessment along Msimbazi River, Tanzania. J.Sci. Res. 17(5), 1-8. DOI: 10.9734/JSRR/2017/38526

9. Chou C-HSJ, Holler J, De Rosa CT (1998) Minimal risk levels (MRLs) for hazardous substances. J Clean Technol Environ Toxicol Occup Med 7(1):1-24

10. Cook $P$ (1993) Interim report on data and methods for assessment of 2, 3, 7, 8-tetrachlorodibenzo-pdioxin risks to aquatic life and associated wildlife

11. Dinç B, Çelebi A, Avaz G, Canlı O, Güzel B, Eren B, Yetis U (2021) Spatial distribution and source identification of persistent organic pollutants in the sediments of the Yeşilırmak River and coastal area in the Black Sea. Mar Pollut Bull 172:112884. https://doi.org/10.1016/j.marpolbul.2021.112884

12. El-Kady AA, Abdel-Wahhab MA, Henkelmann B, Belal MH, Morsi MKS, Galal SM, Schramm K-W (2007) Polychlorinated biphenyl, polychlorinated dibenzo-p-dioxin and polychlorinated dibenzofuran residues in sediments and fish of the River Nile in the Cairo region. Chemosphere 68(9):1660-1668. https://doi.org/10.1016/j.chemosphere.2007.03.066

13. European Commission (2011) Commission Regulation (EU) No 1259/2011 of 2 December 2011 amending Regulation (EC) No 1881/2006 as regards maximum levels for dioxins, dioxin-like PCBs and non dioxin-like PCBs in foodstuffs. Off J Eur Union L 320:18-23

14. Everaert K, Baeyens $\mathrm{J}$ (2002) The formation and emission of dioxins in large scale thermal processes. Chemosphere 46(3):439-448. https://doi.org/10.1016/S0045-6535(01)00143-6

15. Götz R, Bergemann M, Stachel B, Umlauf G (2017) Dioxin in the river Elbe. Chemosphere 183:229241. https:// doi.org/10.1016/j.chemosphere.2017.05.090

Page $12 / 22$ 
16. Huang J, Opoku PA, Guang L, Ke L, Norgbey E (2021) A multi-emission analysis of organic and inorganic pollutants during the combustion of sludge with high and low calorific value coals. Environ. Sci. Pollut. Res.,1-11

17. Jones. K, De Voogt P (1999) Persistent organic pollutants (POPs): state of the science. Environ Pollut 100(1):209-221. https://doi.org/10.1016/S0269-7491(99)00098-6

18. Kassenga G, Mbuligwe SE (2009) Impacts of a Solid Waste Disposal Site on Soil, Surface Water and Groundwater Quality in Dar es Salaam City, Tanzania.Journal of Sustainable Development in Africa, 10

19. Klasmeier J, McLachlan MS (1998) PCDD/Fs in textiles-Part 1: A screening method for detection of octachlorodibenzo-p-dioxin and octachlorodibenzofuran. Chemosphere 36(7):1627-1635. https://doi.org/10.1016/S0045-6535(97)10093-5

20. Kondoro J (1992) Dispension of heavy metals along Msimbazi basin in Dar es Salaam, Tanzania. Tanz J Sci 23:1-10

21. Križanec B, Le Majcen A (2006) Dioxins and dioxin-like persistent organic pollutants in textiles and chemicals in the textile sector. Croat Chem Acta 79(2):177-186. https://hrcak.srce.hr/4120

22. Laroo CA, Schenk CR, Sanchez LJ, McDonald J (2011) Emissions of PCDD/Fs, PCBs, and PAHs from a modern diesel engine equipped with catalyzed emission control systems. Environ Sci Technol 45(15):6420-6428. https://doi.org/10.1021/es104220f

23. Lee KT, Lee JH, Lee JS, Park KH, Kim SK, Shim WJ, Oh JR (2007) Human exposure to dioxin-like compounds in fish and shellfish consumed in South Korea. Hum Ecol Risk Assess 13(1):223-235. https://doi.org/10.1080/10807030601105365

24. Mbuligwe SE, Kaseva ME (2005) Pollution and self-cleansing of an urban river in a developing country: a case study in Dar es Salaam, Tanzania. J Environ Manage 36(2):328-342

25. Mihale MJ (2021) Metal Contamination in Sediments of Coastal Rivers around Dar es Salaam, Tanzania. Huria J 27(2):72-92

26. Mikolajczyk S, Warenik-Bany M, Pajurek M (2021) PCDD/Fs and PCBs in Baltic fish-Recent data, risk for consumers. Mar Pollut Bull 171:112763. https://doi.org/10.1016/j.marpolbul.2021.112763

27. Miraji H, Mureithi E, Othman OC, Ngassapa F (2020) 1-D Transport Behaviour of Emerging Contaminants in the Unidirectional Flowing Surface Waters of the Msimbazi River. Tanz J Sci 46(2):371-382

28. Nieuwoudt C, Quinn LP, Pieters R, Jordaan I, Visser M, Kylin H, Bouwman H (2009) Dioxin-like chemicals in soil and sediment from residential and industrial areas in central South Africa. Chemosphere 76(6):774-783. https://doi.org/10.1016/j.chemosphere.2009.04.064Get rights and content

29. Pan J, Yang Y, Geng C, Yeung L, Cao X, Dai T (2010) Polychlorinated biphenyls, polychlorinated dibenzo-p-dioxins and dibenzofurans in marine and lacustrine sediments from the Shandong Peninsula, China. J hazard Mater 176(1):274-279. https://doi.org/10.1016/j.jhazmat.2009.11.024 
30. Pius C, Koosaletse-Mswela P, Sichilongo K, Dikinya O (2020) Mapping polychlorinated dibenzo-pdioxins/dibenzofurans in soils around Pugu municipal dump site in Dar es Salaam, Tanzania: Implications on dermal and soil ingestion exposure for people in the peripheral. Environ Pollut 258:113665. https://doi.org/10.1007/s11356-018-3629-z

31. Rovira J, Mari M, Nadal M, Schuhmacher M, Domingo JL (2010) Environmental monitoring of metals, PCDD/Fs and PCBs as a complementary tool of biological surveillance to assess human health risks. Chemosphere 80(10):1183-1189. https:// doi.org/10.1016/j.chemosphere.2010.06.016

32. Sawe, S. F., Shilla, D. A., \& Machiwa, J. F. (2021). Lead (Pb) contamination trends in Msimbazi estuary reconstructed from ${ }^{21} \llbracket \mathrm{Pb}$-dated sediment cores Environ. Forensics (Msimbazi River,Tanzania). https://doi.org/10.1080/15275922.2020.1805823

33. Ssebugere P, Kiremire BT, Henkelmann B, Bernhöft S, Kasozi GN, Wasswa J, Schramm K-W (2013) $\mathrm{PCDD} /$ Fs and dioxin-like PCBs in fish species from Lake Victoria, East Africa. Chemosphere 92(3):317-321. https://doi.org/10.1016/j.chemosphere.2013.03.033

34. Shin E-s, Jeong Y, Barghi M, Seo S-H, Kwon SY, Chang Y-S, Fs PCDD (2020) DL-PCBs, HBCDs, TBBPA, and PFASs) in a Bos Taurus. Environ. Pollut., 267, 115306.

https://doi.org/10.1016/j.envpol.2020.115306

35. Sundqvist KL, Tysklind M, Geladi P, Cato I, Wiberg K (2009) Congener fingerprints of tetra-through octa-chlorinated dibenzo-p-dioxins and dibenzofurans in Baltic surface sediments and their relations to potential sources. Chemosphere 77(5):612-620. https://doi.org/10.1016/j.chemosphere.2009.08.057

36. UNEP (2001) Stockholm Convention Retrieved 20/3/2018, from UNEP http://chm.pops.int/Countries/StatusofRatifications/PartiesandSignatoires/tabid/4500/Default.aspx

37. USEPA (1985) Health assessment document for polychlorinated dibenzo -p-dioxins. Washington DC 38. USEPA (1994) Tetra-Through Octa-Chlorinated Dioxins and Furans by Isotope Dilution HRGC/HRMS Revision B, 821/B-94-005 Method 1613: Office of Water Engineering and Analysis Division (4303)

39. USEPA (2008) Method 1668B Chlorinated Biphenyl Congeners in Water, Soil, Sediment, Biosolids, and Tissue by HRGC/HRMS

40. Verta M, Kiviranta H, Salo S, Malve O, Korhonen M, Verkasalo PK, Päätalo K (2009) A decision framework for possible remediation of contaminated sediments in the River Kymijoki, Finland. Environ Sci Pollut Res 16(1):95-105. https://doi.org/10.1007/s11356-008-0061-9

41. Verta M, Salo S, Korhonen M, Assmuth T, Kiviranta H, Koistinen J, Tysklind M (2007) Dioxin concentrations in sediments of the Baltic Sea-A survey of existing data. Chemosphere 67(9):17621775. https://doi.org/10.1016/j.chemosphere.2006.05.125

42. Weber R, Gaus C, Tysklind M, Johnston P, Forter M, Hollert H, Masunaga S (2008) Dioxin-and POPcontaminated sites-contemporary and future relevance and challenges. Environ Sci Pollut Res 15(5):363. https://doi.org/10.1007/s11356-008-0024-1

43. Wirgin I, Chambers RC (2021) Hepatic Burdens of PCB and PCDD/F Congeners in Federally Endangered Shortnose Sturgeon and Atlantic Sturgeon from the Hudson River, New York, USA: 
Burden Patterns and Potential Consequences in Offspring. DOI: https://doi.org/10.21203/rs.3.rs1086966/v1

\section{Figures}

\section{Figure 1}

A sketch of the Msimbazi River and its tributaries showing the sampling points

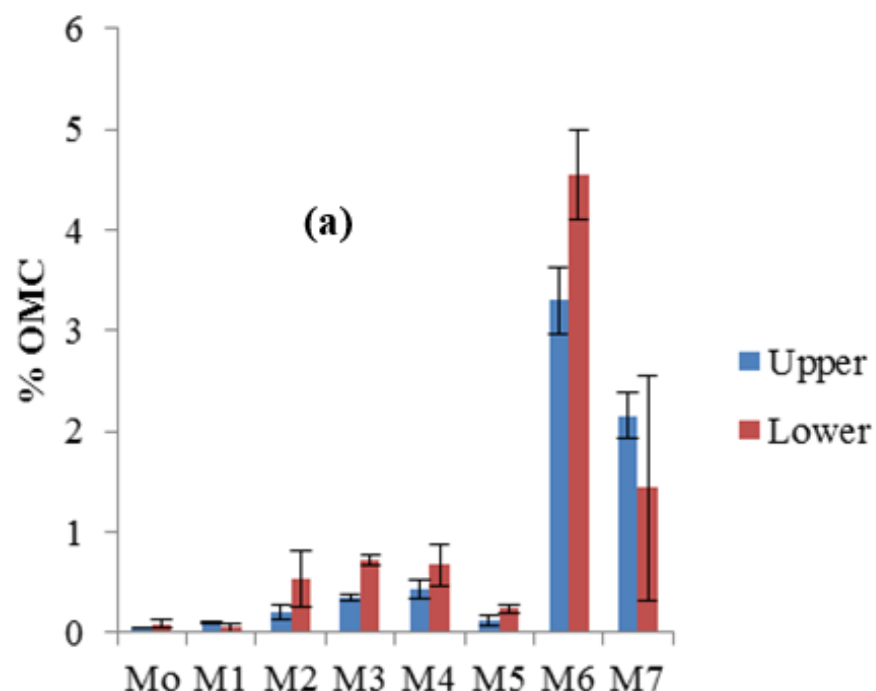

Sampling site

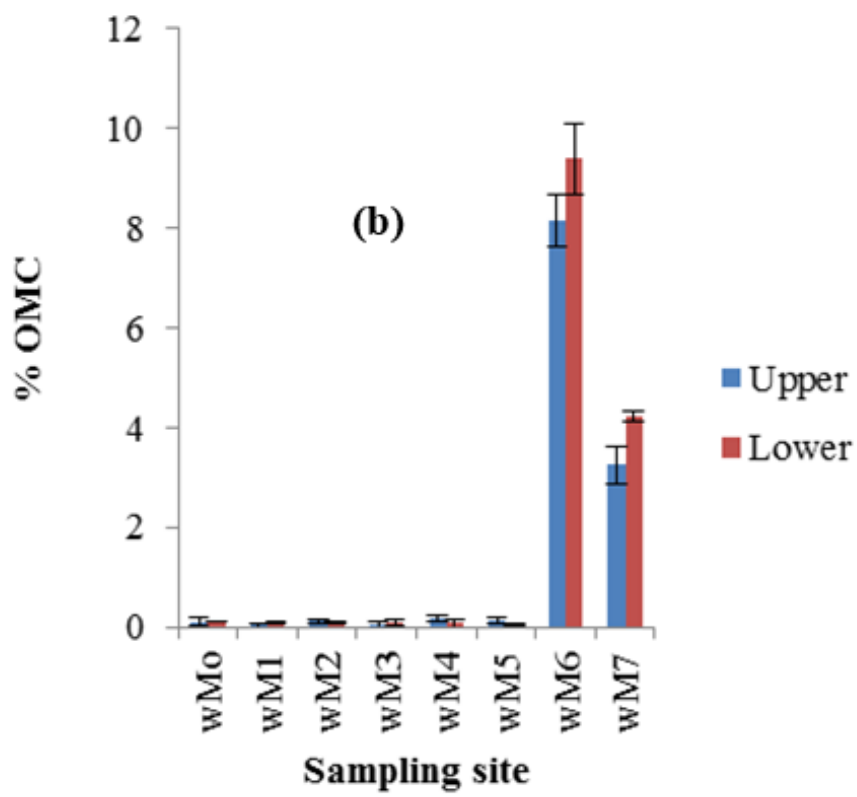

Figure 2

(a) Dry and (b) wet season sediment organic matter content 


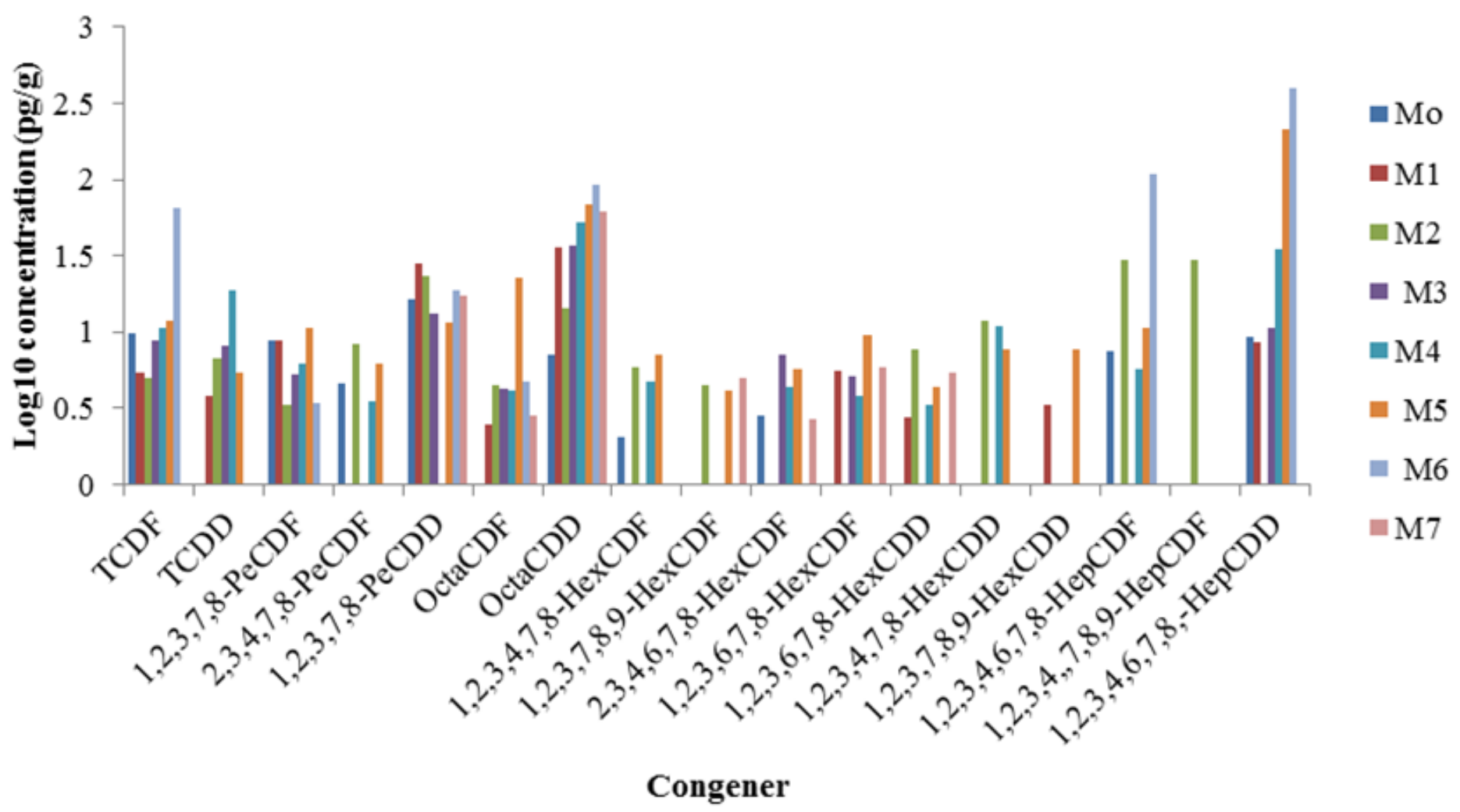

Figure 3

$\log _{10}$ concentration of PCDD/Fs at different sampling sites during the dry season 


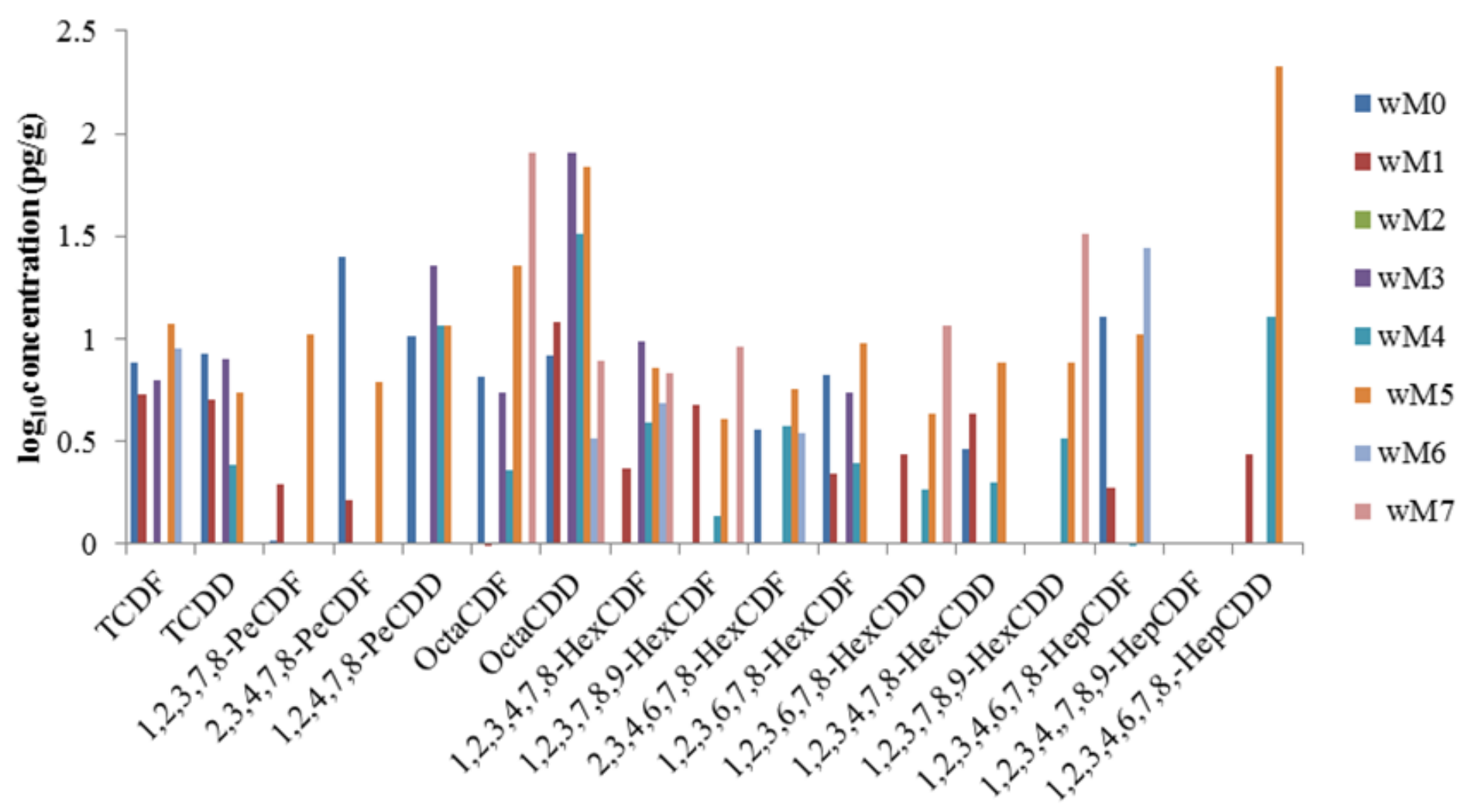

Congeners

Figure 4

$\log _{10}$ concentration of PCDD/Fs at different sampling sites during the wet season
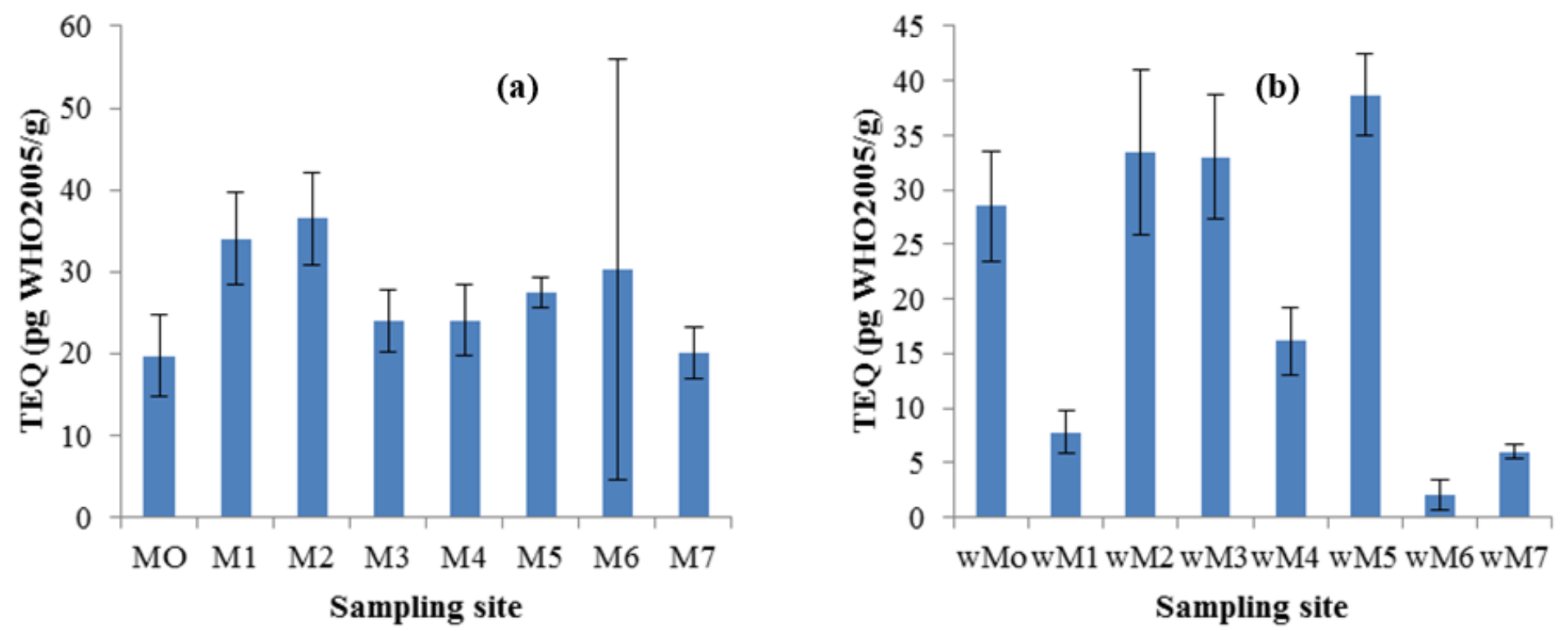

Figure 5 
(a) Dry and (b) wet season TEQ of PCDD/Fs in sediments from Msimbazi River and its tributaries

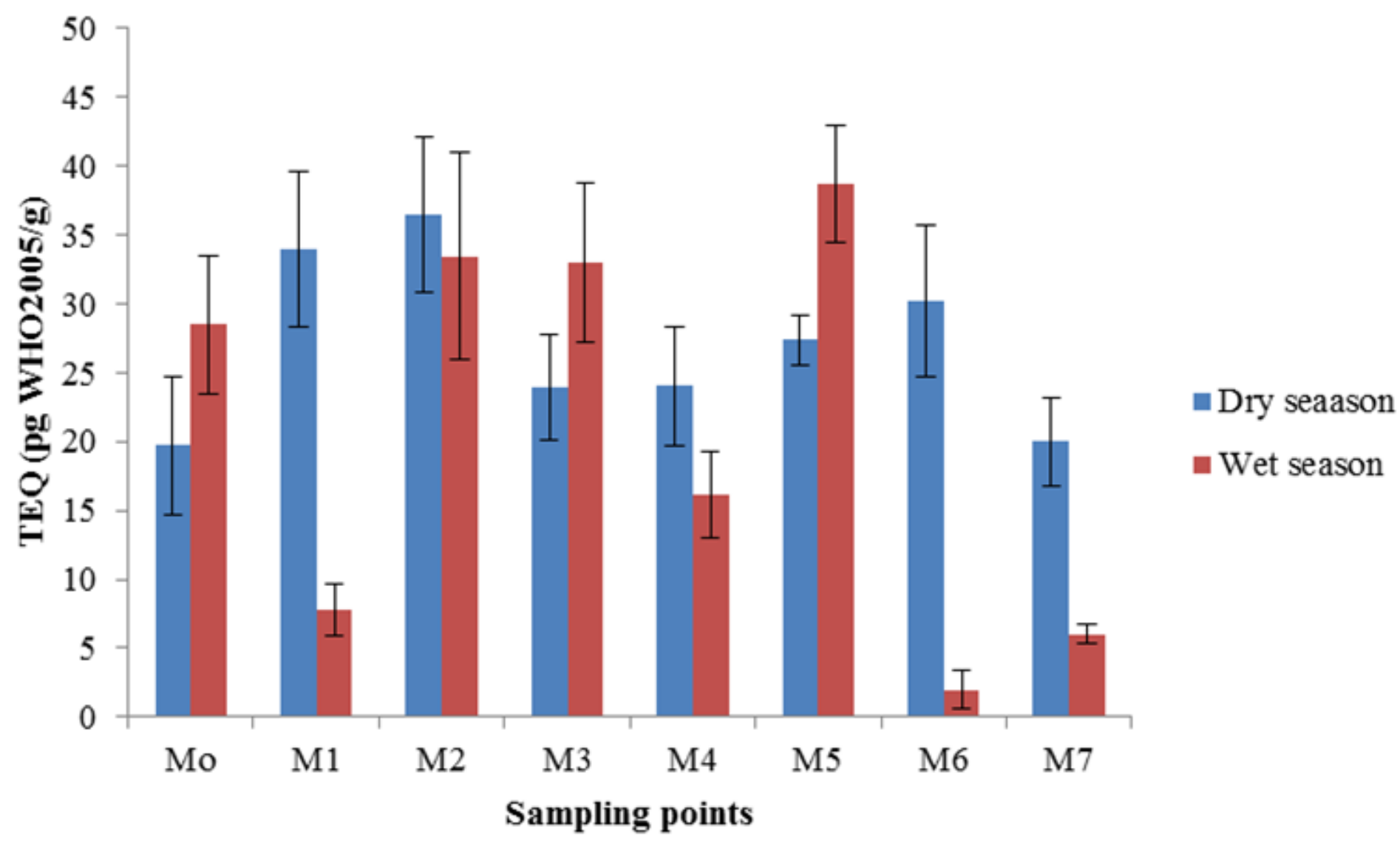

Figure 6

Seasonal variations of PCDD/Fs at different points along Msimbazi river 


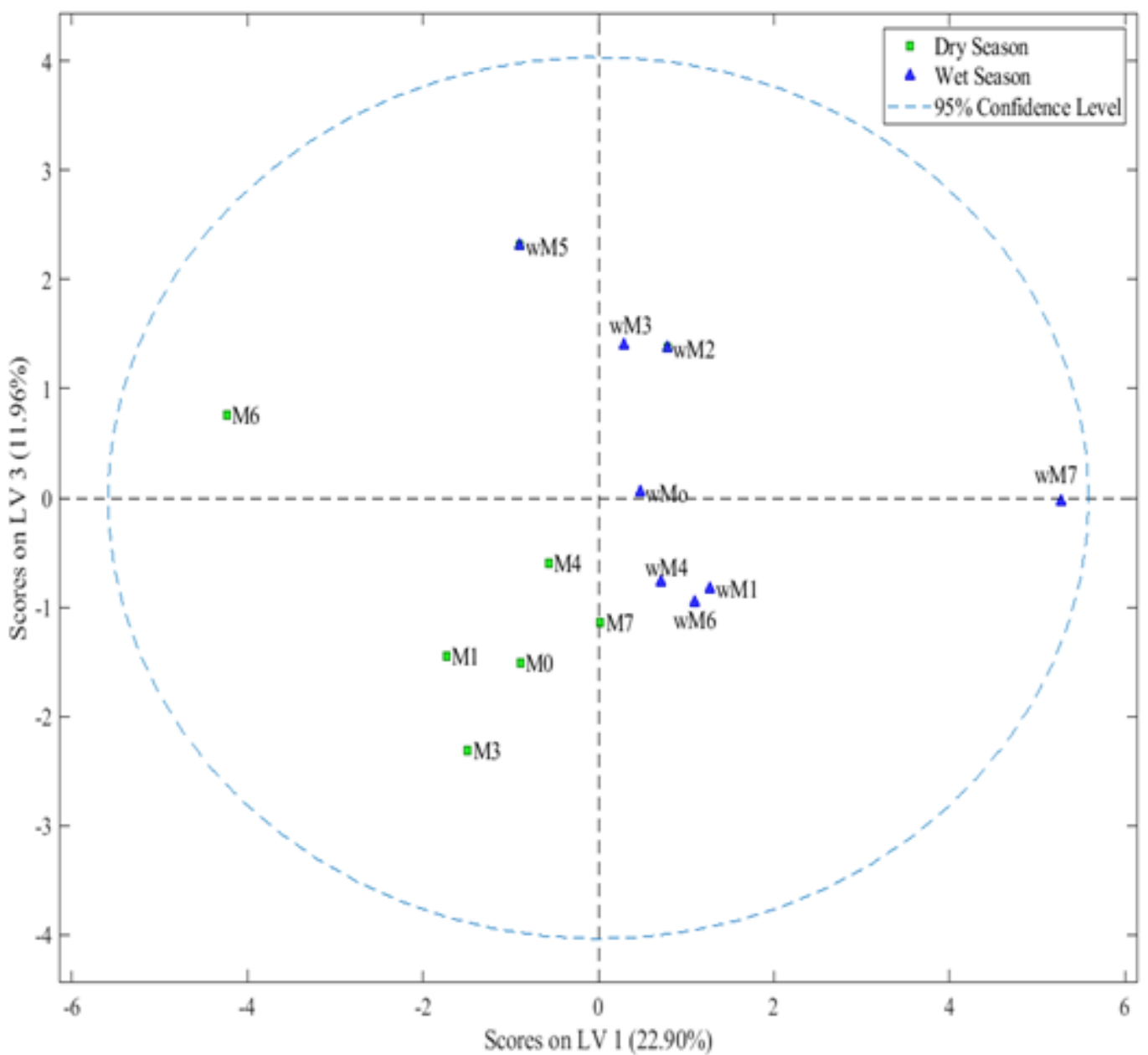

Figure 7

Scores plot of LV 3 versus LV1. 


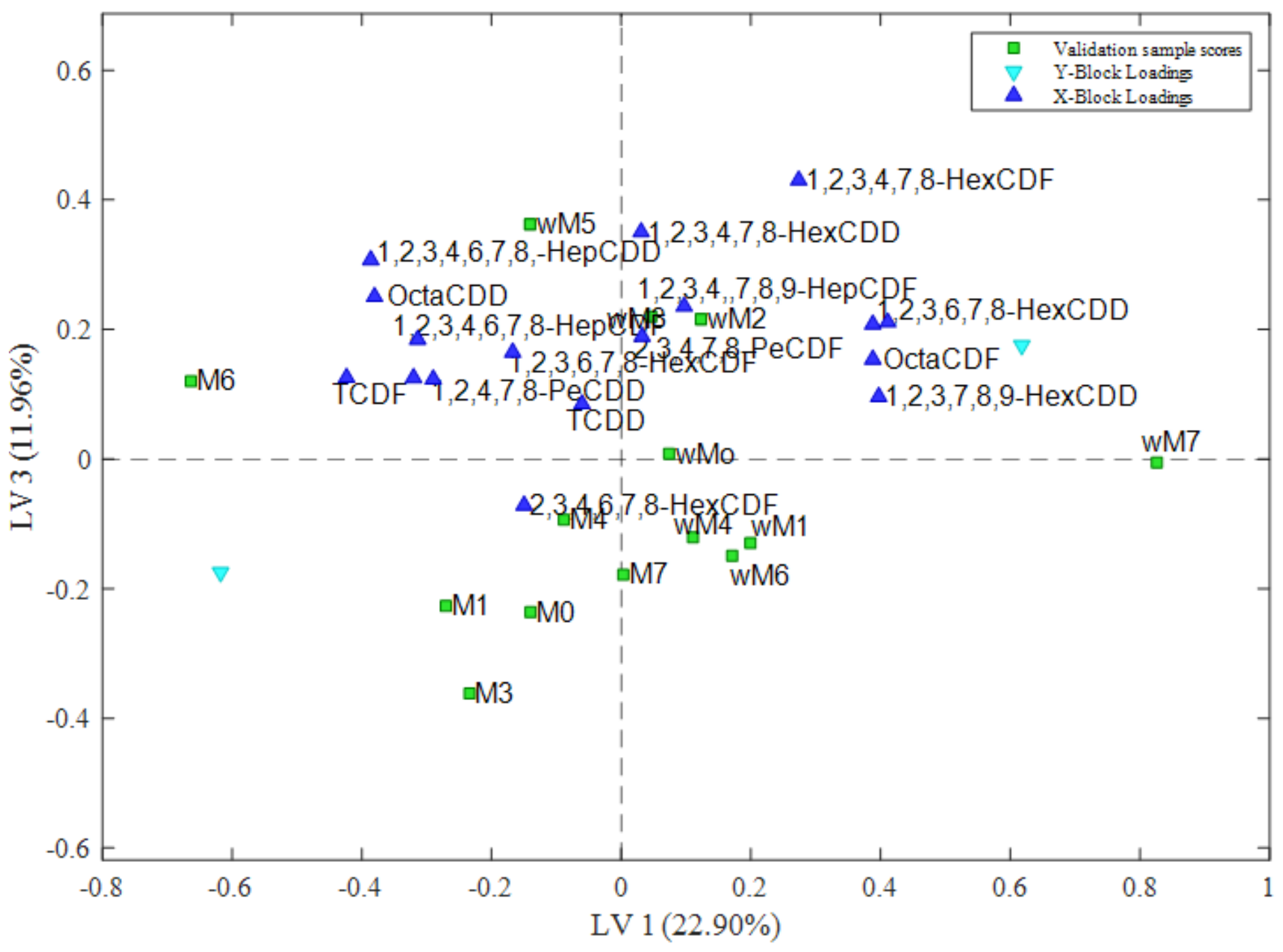

Figure 8

Biplot of LV3 (11.96 \%) versus LV1 (22.90\%) 


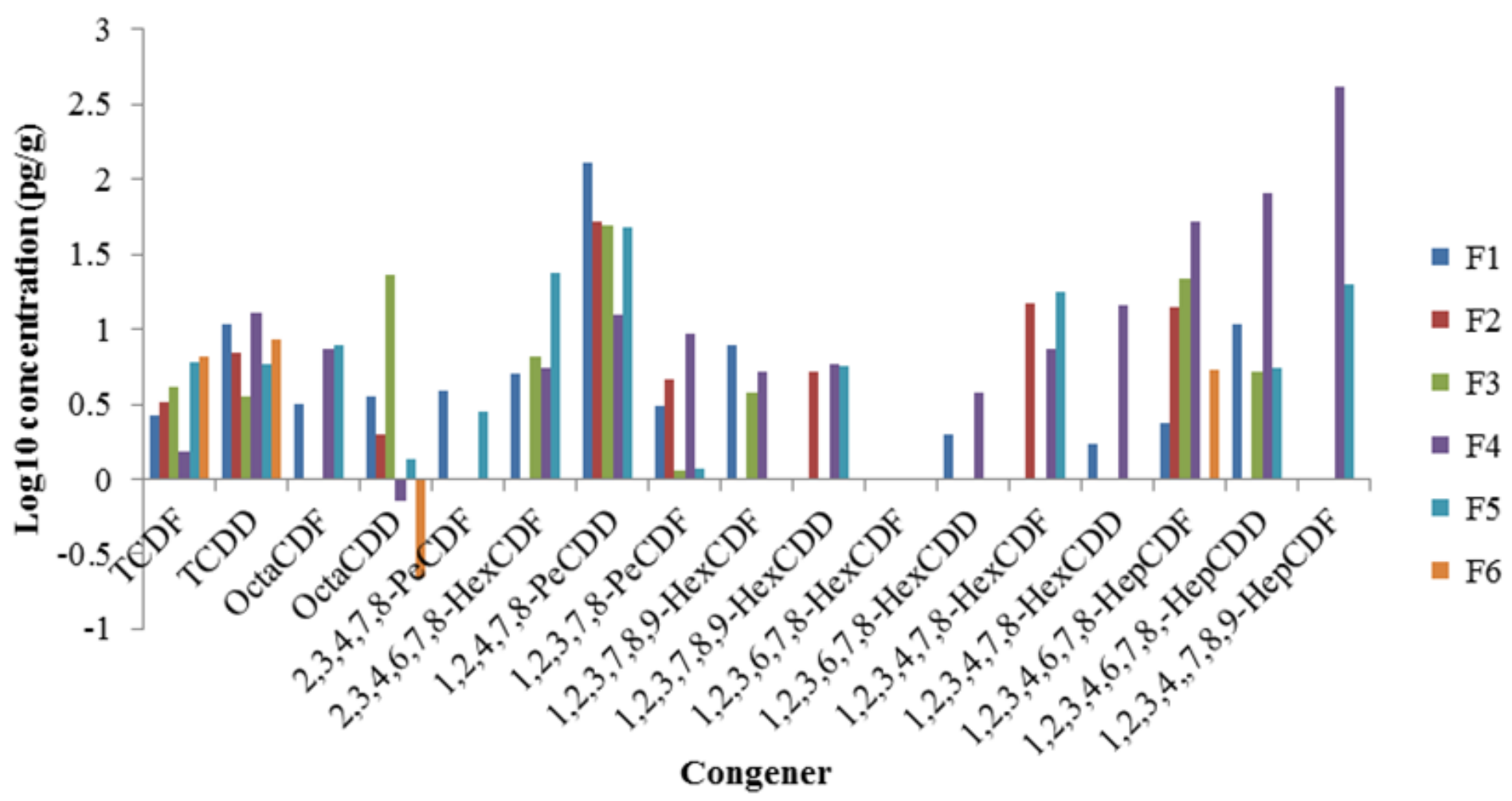

Figure 9

$\log _{10}$ concentrations detected PCDD/Fs in fish samples

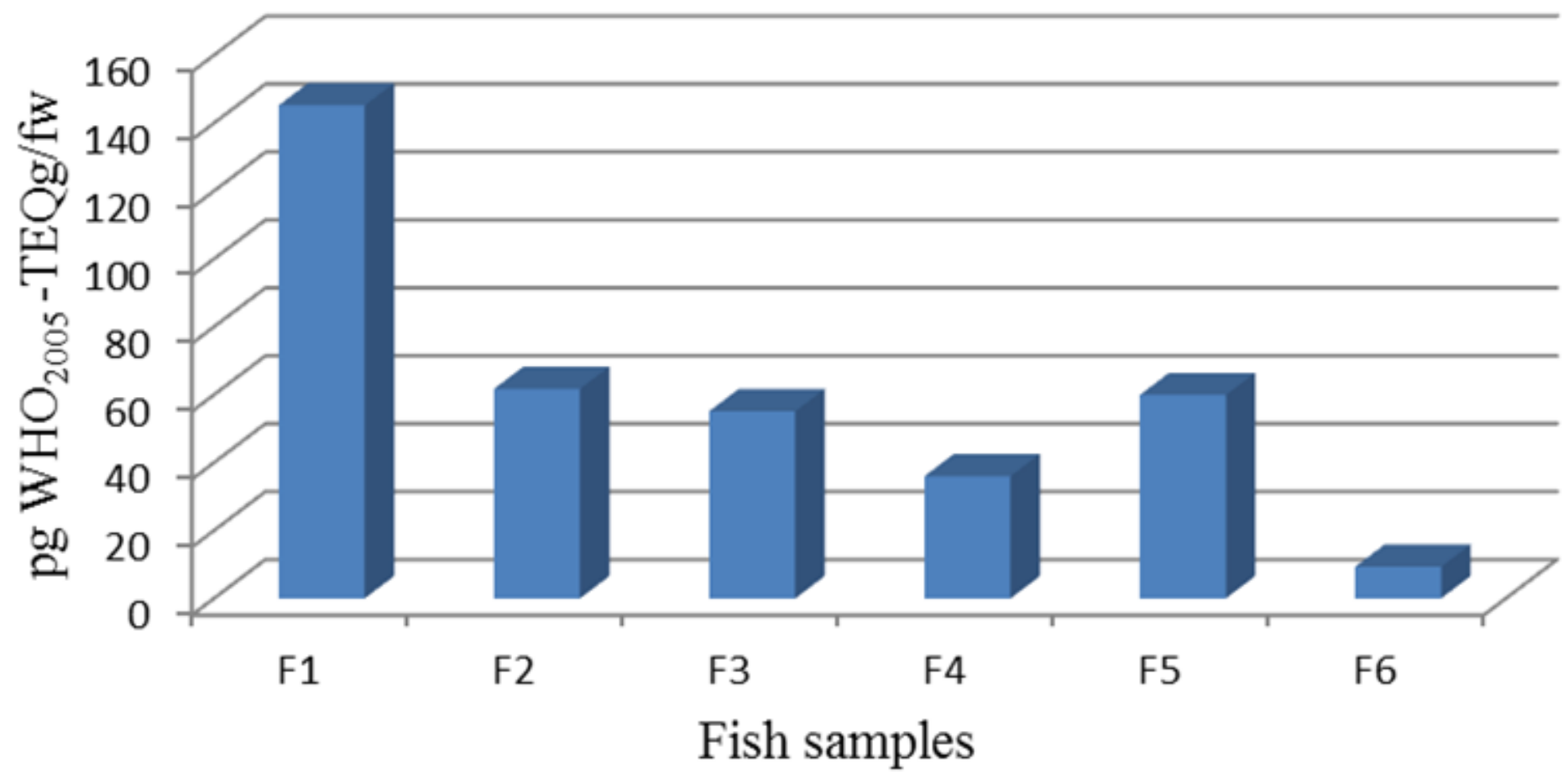

Figure 10 


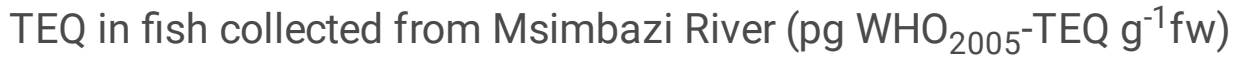

